\title{
Assessing Timely Presentation to Care Among People Diagnosed with HIV During Hospital Admission: A Population-Based Study in Ontario, Canada
}

\author{
Claire E. Kendall 1,2,3,4,5 Esther S. Shoemaker ${ }^{1,2,3}$. Janet Raboud ${ }^{6,7} \cdot$ Amy E. Mark $^{3}$. Ahmed M. Bayoumi An,5,8,9,10 $^{3}$ \\ Ann N. Burchell ${ }^{3,5,6,10} \cdot$ Mona Loutfy $^{3,9,10,11}$. Sean B. Rourke ${ }^{5,8,12}$. Clare E. Liddy ${ }^{1,2}$. Ron Rosenes ${ }^{2} \cdot$ Timothy Rogers $^{13}$. \\ Tony Antoniou $3,5,10$
}

Published online: 13 March 2018

(c) The Author(s) 2018. This article is an open access publication

\begin{abstract}
Timely presentation to care for people newly diagnosed with HIV is critical to optimize health outcomes and reduce onward HIV transmission. Studies describing presentation to care following diagnosis during a hospital admission are lacking. We sought to assess the timeliness of presentation to care and to identify factors associated with delayed presentation. We conducted a population-level study using health administrative databases. Participants were all individuals older than 16 and newly diagnosed with HIV during hospital admission in Ontario, Canada, between April 1, 2007 and March 31, 2015. We used modified Poisson regression models to derive relative risk ratios for the association between sociodemographic and clinical variables and the presentation to out-patient HIV care by 90 days following hospital discharge. Among 372 patients who received a primary HIV diagnosis in hospital, $83.6 \%$ presented to care by 90 days. Following multivariable analysis, we did not find associations between patient sociodemographic or clinical characteristics and presentation to care by 90 days. In a secondary analysis of 483 patients diagnosed during hospitalization but for whom HIV was not recorded as the principal reason for admission, $73.1 \%$ presented to care by 90 days. Following multivariable adjustment, we found immigrants from countries with generalized HIV epidemics (RR 1.265, 95\% CI 1.133-1.413) were more likely to present to care, whereas timely presentation was less likely for people with a mental health diagnosis (RR $0.817,95 \%$ CI $0.742-0.898$ ) and women (RR 0.748, 95\% CI 0.559-1.001). Future work should evaluate mechanisms to facilitate presentation to care among these populations.
\end{abstract}

Keywords HIV/AIDS · Linkage · Care presentation · Cascade $\cdot$ Institute for Clinical Evaluative Sciences (ICES)

Claire E. Kendall

ckendall@uottawa.ca

1 Department of Family Medicine, University of Ottawa, Ottawa, Canada

2 C.T. Lamont Primary Health Care Research Centre, Bruyère Research Institute, 43 Bruyère St., Annex E, Ottawa, ON K1N 5C8, Canada

3 Institute for Clinical Evaluative Sciences, Toronto, Canada

4 Clinical Epidemiology Program, Ottawa Hospital Research Institute, Ottawa, Canada

5 Li Ka Shing Knowledge Institute, St. Michael’s Hospital, Toronto, Canada

6 Dalla Lana School of Public Health, University of Toronto, Toronto, Canada
7 Toronto General Hospital Research Institute, University Health Network, Toronto, Canada

8 Centre for Urban Health Solutions, St. Michael's Hospital, Toronto, Canada

9 Institute of Health Policy, Management and Evaluation, University of Toronto, Toronto, Canada

10 Department of Medicine, University of Toronto, Toronto, Canada

11 Women's College Research Institute, Women's College Hospital, Toronto, Canada

12 Department of Psychiatry, University of Toronto, Toronto, Canada

13 CATIE (Canadian AIDS Treatment Information Exchange), Toronto, Canada 


\section{Introduction}

Presentation to HIV care is a prerequisite for initiating antiretroviral therapy and establishing relationships with health care providers that are conducive to achieving virologic suppression and supporting long-term retention in care [1-4]. In addition to the well documented reductions in HIV-related morbidity and mortality imparted by antiretroviral therapy [4], timely presentation to care is a cornerstone of the test-and-treat approach to preventing further transmission of HIV [4]. In addition, timely presentation can also reduce costs to the health care system because virologically suppressed patients need fewer intensive clinical interventions over time to manage their health than people with a high viral load [2]. Timely presentation to care is associated with improved outcomes for individual patients, public health, and health systems; thus, the proportion of patients completing a visit with an HIV medical provider within 90 days of diagnosis is a commonly adopted metric for characterizing this component of the HIV care continuum [5].

Previous studies have identified several barriers to timely presentation to care among people with HIV, including individual-level factors (e.g. age, sex or gender, income, immigration status) [6-12], psychosocial factors (e.g. mental health status, substance use, homelessness) [13-15], and geographic factors (e.g. rural or remote residence) [16]. Conversely, people are more likely to present to care if they are employed [13].

Diagnosis of HIV during hospital admission may also influence timely linkage to care. While a hospital admission may afford the opportunity for interaction with HIV/ infectious disease specialists and scheduling of outpatient follow-up prior to discharge, it is also possible that patients diagnosed in the inpatient setting represent a particularly marginalized group of high risk individuals. In one study, patients diagnosed with HIV during hospital admission were primarily uninsured men [17]. However, this study was examined in a single center over a short time period (2011-2012). A population-based study examined presentation to care following diagnosis of HIV in outpatient units in Sao Paulo, Brazil and found women sought care earlier than men [18]. However, to our knowledge, no population-based studies in developed regions have studied presentation to care after a diagnosis of HIV in the inpatient setting. These data are important because patients diagnosed during hospitalization are likely to have late HIV disease and experience social or structural barriers to care. Accordingly, we examined the timeliness of presentation to care for people newly diagnosed with HIV as inpatients in Ontario, Canada, and determined which factors were associated with timely presentation following an HIV diagnosis in hospital.

\section{Methods}

\section{Setting}

We conducted a population-based study among people diagnosed with HIV during hospital admission between April 1, 2007 and March 31, 2015 in Ontario, Canada. This study was approved by the Research Ethics Board of Sunnybrook Health Sciences Centre, Toronto, Ontario.

\section{Data Sources}

We used Ontario's administrative health databases, which are securely linked using unique, encoded identifiers, and analyzed at the Institute for Clinical Evaluative Sciences (ICES, www.ices.on.ca). We obtained basic individual demographic data, including age, postal code, and death from the Registered Persons Database, a registry of all Ontario residents eligible for health insurance. We identified adults with a diagnosis of HIV during hospital admission using the Canadian Institute for Health Information's Discharge Abstract Database. We used the Ontario Health Insurance Plan database and the Community Health Centres database to identify claims for physician services. We used the Immigration, Refugees and Citizenship Canada database to identify individuals who had immigrated to Ontario in 1985 or later.

\section{Study Population and Recruitment}

We used the Discharge Abstract Database to identify all adults aged 16 years and older with incident HIV diagnosis during inpatient hospital admission during the study period [International Classification of Diseases (ICD-10) primary discharge diagnosis codes B20-B24]. We restricted the analysis to people who were diagnosed during hospital admission to ensure that our study cohort only consisted of people who were newly diagnosed with HIV. To distinguish an incident from a prevalent diagnosis, we looked back to April 1, 2002 to identify and exclude individuals with previous physician claims or hospital admissions for HIV and associated opportunistic infections (ICD9 codes 042, 043, 044, ICD10 codes B20-B24). We excluded people who died during the index hospital admission. We conducted a secondary analysis and expanded our definition of HIV diagnosis in hospital to include admissions for which HIV was included as any discharge diagnosis, retaining the same exclusions for no previous HIV diagnoses.

\section{Outcomes}

Our primary outcome was delayed presentation to care, defined as no outpatient encounter for HIV care (a visit 
with ICD billing code 042,043 , or 044) by 90 days of the index hospital discharge [19-22].

\section{Analysis}

We compared baseline characteristics between individuals with and without delayed presentation to care using summary statistics. We used modified Poisson regression [23] to determine characteristics associated with delayed presentation to care, including patient age and sex, urban versus rural residence, neighborhood income quintile as a proxy for socioeconomic status, co-morbidity burden in the preceding year, number of primary care visits in the preceding year, whether the admitting hospital was an academic or community institution, and immigration status, which was categorized as immigrants from HIV prevalent countries, immigrants from non-HIV prevalent countries, and Canadian born or long-term residents of Canada (immigration status data dates back only to 1985). We assigned patient socioeconomic status at the neighborhood level using postal code information and Statistics Canada census data. We also used postal code information to assign urban, non-major urban, or rural residence [24] to be able to control for neighbourhood of residence, while direct inference of neighbourhood-level effects was not evaluated in this study. We used the Johns Hopkins Adjusted Clinical Groups Case-Mix System to adjust for differences in comorbidity burden [25]. This system uses diagnostic information from administrative databases to describe and predict level of comorbidity and use of health care resources. In this study, we used Aggregated Diagnosis Groups (ADGs), which are clusters of diagnostic codes that are similar in terms of severity and expected persistence, ranging from a low level of comorbidity of 0 to the highest level of 32 . We categorized comorbidity as low (0-5 ADGs), medium (6-9 ADGs) and high (10 + ADGs). We used a validated approach to ascertain whether participants had a mental health diagnosis [26]. We counted the number of primary care visits in the previous year and categorized these as $0-2$ visits, $3-5$ visits, 6-8 visits, or 9+ visits. We repeated these analyses for our secondary analysis cohort. Cell sizes of 6 or less are reported in aggregate only to preserve privacy. All analyses were conducted using SAS ${ }^{\circledR}$ software version 9.3 [27].

\section{Role of the Funding Source}

The study was funded by the Canadian Institutes of Health Research (CIHR) FRN TT5-128270. CIHR had no role in the design of the study, the collection, analysis, and interpretation of the data, and the reporting of the findings.

\section{Results}

\section{Sample Description}

Over the course of the study, 399 people had a primary diagnosis of HIV during hospital admission in Ontario, of whom 27 (6.8\%) individuals were excluded from the analysis because they died within 90 days of hospital discharge. Our cohort had a mean age of 44 years (SD 11.6 years) and $16.7 \%$ were women (Table 1). Most patients lived in urban centres $(\mathrm{n}=328,88.2 \%)$, were Canadian born or long term residents of Canada $(n=289,77.7 \%)$, and lived in the two lowest income quintile neighborhoods $(\mathrm{n}=197,52.9 \%)$. We observed a high rate of comorbidities, with 245 (65.9\%) of individuals being in the highest comorbidity category and 123 (33.1\%) experiencing a mental health condition in the previous 2 years (Table 1 ).

The median (interquartile range [IQR]) length of hospital stay was 13 (7-28) days; 17 (3.5\%) left the hospital against medical advice. Almost half of people diagnosed with HIV $(\mathrm{n}=165,44.4 \%)$ saw an infectious disease physician during their hospital stay. The proportion of patients who presented to care for individuals with a primary HIV diagnosis during admission was $66.4 \%$ within 30 days and $83.6 \%$ within 90 days. By 365 days, $89.2 \%$ of people had presented to care.

\section{Bivariate Statistics: Primary Analysis}

The length of hospital stay did not differ between patients who presented to care by 90 days and those who did not [13 median days (IQR 8-28) versus 10 median days (IQR 5-29) $(\mathrm{p}=0.15)]$. Those who presented to care by 90 days were more likely to be seen by an infectious disease specialist during admission ( $\mathrm{n}=150,48.2 \%$ vs. $\mathrm{n}=15,24.6 \%, \mathrm{p}<0.001)$, and were less likely to leave the hospital against medical advice ( $\mathrm{n}=7,2.3 \%$ vs. $\mathrm{n} \leq 10, \leq 16 \%, \mathrm{p}=0.003)$ than people who presented to care later than 90 days following their HIV diagnosis (Table 2).

\section{Bivariate Statistics: Secondary Analysis}

In the secondary analysis, we identified 483 patients for whom HIV was not recorded as the primary diagnosis at the time of discharge. This sample included more women than the cohort of people with a primary diagnosis of HIV during admission ( $n=102,21.1 \%$ versus $n=62,16.7 \%$ ), but we observed no other major demographic differences between the cohorts (Table 1). 
Table 1 Demographic characteristics of people diagnosed with HIV during hospital admission in Ontario, Canada by type of HIV diagnosis

\begin{tabular}{|c|c|c|}
\hline Variable & $\begin{array}{l}\mathrm{HIV} \text { as primary diagnosis } \\
\mathrm{n}=372\end{array}$ & $\begin{array}{l}\mathrm{HIV} \text { as any diagnosis } \\
\mathrm{n}=483\end{array}$ \\
\hline \multicolumn{3}{|l|}{ Patient characteristics } \\
\hline \multicolumn{3}{|l|}{ Year of diagnosis } \\
\hline $2007 / 2008$ & $56(15.1)$ & $74(15.3)$ \\
\hline $2008 / 2009$ & $49(13.2)$ & $65(13.5)$ \\
\hline $2009 / 2010$ & $44(11.8)$ & $52(10.8)$ \\
\hline $2010 / 2011$ & $51(13.7)$ & $63(13.0)$ \\
\hline $2011 / 2012$ & 49 (13.2) & $65(13.5)$ \\
\hline $2012 / 2013$ & $40(10.8)$ & $51(10.6)$ \\
\hline $2013 / 2014$ & 48 (12.9) & $62(12.8)$ \\
\hline 2014/2015 & $35(9.4)$ & $51(10.6)$ \\
\hline Age (mean, SD) & $43.52(11.60)$ & $43.79(11.80)$ \\
\hline \multicolumn{3}{|l|}{ Age category } \\
\hline$<=25$ & $19(5.1)$ & $26(5.4)$ \\
\hline $26-35$ & $70(18.8)$ & $88(18.2)$ \\
\hline $36-45$ & $140(37.6)$ & $168(34.8)$ \\
\hline $46-55$ & $89(23.9)$ & $132(27.3)$ \\
\hline$>56$ & $54(14.5)$ & $69(14.3)$ \\
\hline Female & $62(16.7)$ & $102(21.1)$ \\
\hline \multicolumn{3}{|l|}{ Income quintile } \\
\hline 1 & $127(34.1 \%)$ & $174(36.0)$ \\
\hline 2 & $70(18.8 \%)$ & $91(18.8)$ \\
\hline 3 & $55(14.8 \%)$ & $68(14.1)$ \\
\hline 4 & $58(15.6 \%)$ & 77 (15.9) \\
\hline $5+$ missing $^{\mathrm{b}}$ & $62(16.7 \%)$ & $73(15.1)$ \\
\hline \multicolumn{3}{|l|}{ Rurality } \\
\hline Major urban & $328(88.2)$ & $422(87.4)$ \\
\hline Non major urban & $27(7.3)$ & $35(7.2)$ \\
\hline Rural & $17(4.6)$ & $26(5.4)$ \\
\hline Number of $\mathrm{ADGs}^{\mathrm{c}}$ in 2 years prior to cohort entry (Median (IQR)) & $11(8-13)$ & $11(8-14)$ \\
\hline Low comorbidity (0-5 ADGs) & $7(1.9)$ & $10(2.1)$ \\
\hline Medium comorbidity (6-9 ADGs) & $120(32.3)$ & $153(31.7)$ \\
\hline High comorbidity ( $>=10$ ADGs) & $245(65.9)$ & $320(66.3)$ \\
\hline \multicolumn{3}{|l|}{ Immigrant status } \\
\hline Canadian born or long-term resident & 289 (77.7) & $385(79.7)$ \\
\hline Immigrant, country without generalized HIV epidemics & $39(10.5)$ & $47(9.7)$ \\
\hline Immigrant, country with generalized HIV epidemics & $44(11.8)$ & $51(10.6)$ \\
\hline Number of primary care visits in year prior to cohort entry Median (IQR) & $5(2-8)$ & $5(2-9)$ \\
\hline Mental Health Diagnosis (yes) & $123(33.1)$ & $178(36.9)$ \\
\hline \multicolumn{3}{|l|}{ Index event characteristics } \\
\hline Hospital admission that started in the Emergency Department & $337(90.6)$ & $431(89.2)$ \\
\hline Length of stay in hospital in day (Median (IQR)) & $13(7-28)$ & $11(7-26)$ \\
\hline \multicolumn{3}{|l|}{ Primary admission diagnosis } \\
\hline HIV & $357(96.0 \%)$ & $363(75.2)$ \\
\hline Infectious Causes & $\leq 5$ & $\leq 20$ \\
\hline Other & $\leq 15$ & $100(20.7)$ \\
\hline Seen by Infectious Disease Specialist during admission (yes) & $165(44.4)$ & $190(39.3)$ \\
\hline Left against medical advice & $13(3.5)$ & $18(3.7)$ \\
\hline \multicolumn{3}{|l|}{ Hospital characteristics } \\
\hline Teaching hospital (yes) & $198(53.2)$ & $269(55.7)$ \\
\hline
\end{tabular}

Results are presented as N (\%), mean (standard deviation), or median (interquartile range)

${ }^{a}$ Cell sizes $<6$ are not reported to ensure privacy

${ }^{b}$ Missing category collapsed due to small cell sizes

${ }^{c}$ Aggregated Diagnosis Groups 


\section{Multivariable Statistics}

Following multivariable adjustment, we did not find any patient characteristics to be associated with delayed presentation to care in our primary analysis. However, in the secondary multivariable analysis that was extended to patients with HIV as primary or any hospital diagnosis, we found successful presentation to care by 90 days more likely for immigrants from countries with generalized HIV epidemics compared to long-term residents of Canada (RR 1.265, 95\% CI 1.133-1.413) and people with a high (10 + ADGs) comorbidity burden (RR 1.631, 95\% CI 0.997-2.669) compared to living with low comorbidity ( $0-5$ ADGs). We found that patients were less likely to present to care in a timely manner if they had a mental health diagnosis (RR 0.817, 95\% CI 0.742-0.898). Women were also less likely to present to care by 90 days (RR $0.748,95 \%$ CI $0.559-1.001$ ) (Table 3).

\section{Discussion}

In our population-based study of people who were diagnosed with HIV during hospital admission in Ontario, Canada, we observed that while the majority of patients with HIV as their primary diagnosis $(83.6 \%)$ and with HIV as any diagnosis $(73.1 \%)$ presented to care by 90 days, a sizeable minority did not present to care in a timely manner, particularly women, and people with mental health diagnoses. People who had a consultation with an infectious disease specialist, immediately following their HIV diagnosis at the hospital, were more likely to present to care by 90 days.

The finding that men appear to be more likely to present to care by 90 days is consistent with previous research from the United States [28]. Moore [29] describes that women face barriers such as having to find accessible and affordable child care that might prevent them from initiating care. Furthermore, women who are newly diagnosed with HIV have been found to be more likely to experience depressive symptoms than men [30], and depression is independently associated with lower rates of presentation to care [9]. This finding has particular implications in our setting, where the proportion of new infections among women is increasing [29].

We further found that people who have emigrated from a country with generalized HIV epidemics were more likely to present to care by 90 days than long-term residents of Canada. This finding is different from European settings, where immigrants from countries in Sub-Saharan Africa were less likely to present to a care provider to control their HIV infection [15]. Previous Canadian research has also found a higher engagement in HIV care with lower rates of loss to follow-up in care after care presentation among recent immigrants compared to long-term residents [31]. HIV care and social services for immigrant communities are often well integrated in Ontario, Canada [32], which could facilitate timely care presentation. Finally, it is possible that immigrant communities in Canada face fewer systemic barriers to care than immigrants to other countries, given our single payer, universal health care system.

People with a high number of comorbidities are high users of the health system and tend to be well engaged in care in Canada [33]. Correspondingly, we found in our cohort that people with greater comorbidity were more likely to have timely presentation to care, likely associated with increased opportunities for care. However, people with a mental health diagnosis were significantly less likely to present to care by 90 days. This is consistent with previous literature in which people with HIV and concurrent mental health conditions have been found to be less likely to adhere to antiretroviral treatment [34] and to be retained in care [35] to achieve an undetectable viral load, in part related to stigmatization [36]. Given the complexity and multifaceted nature of the barriers to present to and engage in HIV care for people with concurrent mental illness, strategies that integrate mental health with HIV primary care, such as co-location of services [36] or home visits by nurses and transition managers, are critical to presentation to and retention in care [37].

Our study builds on previous research in several ways. Although other studies have characterized risk factors for delayed linkage to care, we examined this outcome specifically for those individuals diagnosed during a hospital admission. These individuals may represent particularly marginalized patients for whom linkage to care may be especially challenging. Our finding that individuals with co-existing mental health conditions were less likely to present to care within 90 days supports this assertion, and highlights the need for additional supports for these patients following discharge, such as case coordination and/or home care. Similarly, the finding that women were less likely to present to care than men suggests that measures to prevent loss to follow-up of women following discharge are required, including assistance with transportation and child care.

Our study has a number of strengths and limitations. Using population level data allowed us to examine the incidence of care presentation among all residents of Ontario who have been newly diagnosed with HIV. We excluded 4997 people from the study due to a previous HIV diagnosis and we only included people with a new diagnosis starting in 2002 to avoid bias because the ICD diagnostic codes changed in 2002. We used validated administrative billing code data to ascertain people who were newly diagnosed with HIV rather than laboratory diagnoses. We focused our analyses on patients diagnosed during hospital admission, and our findings may therefore not be generalizable to patients diagnosed in other settings. However, 
Table 2 Demographic characteristics of people with a primary diagnosis of HIV during hospital admission in Ontario, Canada by presentation to care status at 90 days

\begin{tabular}{|c|c|c|c|}
\hline & $\begin{array}{l}\text { Presentation }<90 \text { days } \\
\mathrm{n}=311\end{array}$ & $\begin{array}{l}\text { Presentation } 90+\text { days } \\
\mathrm{n}=61\end{array}$ & $\mathrm{p}$-value \\
\hline \multicolumn{4}{|l|}{ Patient characteristics } \\
\hline \multicolumn{4}{|l|}{ Year of diagnosis } \\
\hline $2007 / 2008$ & $49(15.8)$ & $7(11.5)$ & \multirow[t]{8}{*}{0.47} \\
\hline $2008 / 2009$ & $40(12.9)$ & $9(14.8)$ & \\
\hline $2009 / 2010$ & $35(11.3)$ & $9(14.8)$ & \\
\hline $2010 / 2011$ & $42(13.5)$ & $9(14.8)$ & \\
\hline $2011 / 2012$ & $\leq 50$ & $\leq 5$ & \\
\hline $2012 / 2013$ & $34(10.9)$ & $6(9.8)$ & \\
\hline $2013 / 2014$ & $36(11.6)$ & $12(19.7)$ & \\
\hline $2014 / 2015$ & $\leq 40$ & $\leq 5$ & \\
\hline Age (mean, SD) & $44.07(11.52)$ & 40.69 (11.66) & 0.037 \\
\hline \multicolumn{4}{|l|}{ Age category } \\
\hline$<=25$ & $12(3.9)$ & $7(11.5)$ & \multirow[t]{5}{*}{0.069} \\
\hline $26-35$ & $55(17.7)$ & $15(24.6)$ & \\
\hline $36-45$ & $120(38.6)$ & $20(32.8)$ & \\
\hline $46-55$ & $78(25.1)$ & $11(18.0)$ & \\
\hline$>56$ & $46(14.8)$ & $8(13.1)$ & \\
\hline Female & $48(15.4)$ & $14(23.0)$ & 0.150 \\
\hline \multicolumn{4}{|l|}{ Income quintile } \\
\hline 1 & $103(33.1)$ & $24(39.3)$ & \multirow[t]{5}{*}{0.638} \\
\hline 2 & $60(19.3)$ & $10(16.4)$ & \\
\hline 3 & $44(14.1)$ & $11(18.0)$ & \\
\hline 4 & $49(15.8)$ & $9(14.8)$ & \\
\hline $5+\operatorname{missing}^{\mathrm{b}}$ & $55(17.7)$ & $7(11.5)$ & \\
\hline \multicolumn{4}{|l|}{ Rurality } \\
\hline Major urban & $271(87.1)$ & $57(93.4)$ & \multirow[t]{3}{*}{0.341} \\
\hline Non major urban & $\leq 25$ & $\leq 5$ & \\
\hline Rural & $\leq 20$ & $\leq 5$ & \\
\hline Number of $\mathrm{ADGs}^{\mathrm{c}}$ (median, IQR) in 2 years prior to cohort entry & $11(8-13)$ & $11(7-14)$ & 0.816 \\
\hline Low-Medium comorbidity (0-9 ADGs) & $103(33.1)$ & $24(39.3)$ & 0.137 \\
\hline High comorbidity (>=10 ADGs) & $208(66.9)$ & $37(60.7)$ & \\
\hline \multicolumn{4}{|l|}{ Immigrant status } \\
\hline Canadian born or long-term resident & $242(77.8)$ & $47(77.0)$ & \multirow[t]{3}{*}{0.694} \\
\hline Immigrant, country without generalized HIV epidemics & $31(10.0)$ & $8(13.1)$ & \\
\hline Immigrant, country with generalized HIV epidemics & $38(12.2)$ & $6(9.8)$ & \\
\hline Number of primary care visits in year prior to cohort entry (Median (IQR)) & $5(2-8)$ & $4(1-9)$ & 0.618 \\
\hline Mental Health Diagnosis (yes) & $99(31.8)$ & $24(39.3)$ & 0.254 \\
\hline \multicolumn{4}{|l|}{ Index event characteristics } \\
\hline Hospital admission that started in the Emergency Department & $285(91.6)$ & $52(85.2)$ & 0.118 \\
\hline Length of stay in hospital days (median (IQR)) & $13(8-28)$ & $10(5-29)$ & 0.147 \\
\hline \multicolumn{4}{|l|}{ Primary admission diagnosis } \\
\hline HIV & $298(95.8)$ & $59(96.7)$ & \multirow[t]{3}{*}{0.583} \\
\hline Infectious causes & $\leq 5$ & $0(0.0)$ & \\
\hline Other & $\leq 10$ & $\leq 5$ & \\
\hline Seen by Infectious Disease Specialist during admission (yes) & $150(48.2)$ & $15(24.6)$ & $<0.001$ \\
\hline Left against medical advice (yes) & $7(2.3)$ & $\leq 10$ & 0.003 \\
\hline \multicolumn{4}{|l|}{ Hospital characteristics } \\
\hline Teaching hospital (yes) & $165(53.1)$ & $33(54.1)$ & 0.881 \\
\hline
\end{tabular}

Results are presented as N (\%), mean (standard deviation), or median (interquartile range)

${ }^{\mathrm{a}}$ Cell sizes $<6$ are not reported to ensure privacy

${ }^{b}$ Missing category collapsed due to small cell sizes

${ }^{\mathrm{c}}$ Aggregated Diagnosis Groups 
Table 3 Relative risk for presentation to care by 90 days for people diagnosed with HIV during hospital admission as their main or as any diagnosis

\begin{tabular}{|c|c|c|c|c|}
\hline \multirow[t]{3}{*}{ Covariate } & \multicolumn{4}{|c|}{ Linkage to care by 90 days post discharge } \\
\hline & \multicolumn{2}{|c|}{$\begin{array}{l}\text { Main diagnosis of HIV at discharge } \\
(\mathrm{n}=372)\end{array}$} & \multicolumn{2}{|c|}{ Any diagnosis of HIV $(n=483)$} \\
\hline & RR (95\%CL) & p-value & RR (95\%CL) & p-value \\
\hline \multicolumn{5}{|l|}{ Patient covariates } \\
\hline Age (continuous) & $1.003(0.995-1.008)$ & 0.117 & 1. $(0.949-1.054)$ & 0.9988 \\
\hline \multicolumn{5}{|l|}{ Sex } \\
\hline Male & Referent & & Referent & \\
\hline Female & $0.916(0.729-1.152)$ & 0.454 & $0.748(0.559-1.001)$ & 0.0509 \\
\hline \multicolumn{5}{|l|}{ ADG category } \\
\hline High, $10+$ ADGs & $1.549(0.951-2.525)$ & 0.0788 & $1.631(0.997-2.669)$ & 0.0513 \\
\hline Medium, 6-9 ADGs & $1.478(0.929-2.352)$ & 0.0992 & $1.46(0.907-2.351)$ & 0.1194 \\
\hline Low, 0-5 ADGs & Referent & & & \\
\hline Mental Health & $0.942(0.87-1.021)$ & 0.1436 & $0.817(0.742-0.898)$ & $<0.0001$ \\
\hline \multicolumn{5}{|l|}{ Income quintile } \\
\hline 1 (lowest) & $0.942(0.821-1.082)$ & 0.4001 & $0.916(0.78-1.076)$ & 0.2842 \\
\hline 2 & $0.961(0.845-1.094)$ & 0.5479 & $0.904(0.784-1.043)$ & 0.1664 \\
\hline 3 & $0.923(0.777-1.095)$ & 0.3554 & $0.903(0.717-1.136)$ & 0.3831 \\
\hline 4 & $0.96(0.855-1.078)$ & 0.489 & $0.861(0.733-1.01)$ & 0.0655 \\
\hline 5 (Highest) & Referent & & Referent & \\
\hline \multicolumn{5}{|l|}{ Rurality } \\
\hline Rural & $1.101(0.955-1.268)$ & 0.1844 & $0.986(0.796-1.22)$ & 0.8931 \\
\hline Suburban & $1.064(0.918-1.232)$ & 0.4103 & $0.98(0.831-1.157)$ & 0.8136 \\
\hline Urban & Referent & & Referent & \\
\hline \multicolumn{5}{|l|}{ Immigration status } \\
\hline Immigrant, country without generalized HIV epidemics & $0.952(0.813-1.115)$ & 0.5415 & $1.265(1.133-1.413)$ & $<0.0001$ \\
\hline Immigrant, country with generalized HIV epidemics & $1.107(0.997-1.228)$ & 0.0563 & $0.79(0.451-1.382)$ & 0.4082 \\
\hline Canadian born or long-term resident & Referent & & Referent & \\
\hline \multicolumn{5}{|l|}{ Number of primary care visits before index } \\
\hline $0-2$ & $1.03(0.884-1.199)$ & 0.7086 & $1.006(0.859-1.177)$ & 0.9458 \\
\hline $3-5$ & $1.07(0.978-1.171)$ & 0.1402 & $1.114(0.984-1.26)$ & 0.0874 \\
\hline $6-8$ & $1.047(0.934-1.174)$ & 0.428 & $1.137(0.998-1.296)$ & 0.0539 \\
\hline $9+$ & Referent & & Referent & \\
\hline \multicolumn{5}{|l|}{ Hospital covariates } \\
\hline Teaching hospital & $1.02(0.903-1.153)$ & 0.7454 & $0.999(0.869-1.149)$ & 0.9875 \\
\hline
\end{tabular}

the demographic profile of our cohort is consistent with public health estimates by the province of Ontario [38]. Due to overall small numbers, our differences may not have met statistical significance; however, an association may still be clinically important as the goal is to link all people with HIV to care and to start treatment in a timely manner. Finally, ICES data are collected for administrative rather than research purposes, thus social variables such as income are ascertained using neighborhood-level metrics (postal codes).

\section{Conclusion}

The presentation of people diagnosed with HIV to care in a timely fashion is critical to improve their health outcomes [1] and to reduce the risks associated with possible transmission of HIV [39]. Our findings can be applied to guide targeted interventions, such as same day testing and initiation of treatment among both, inpatients and outpatient settings [40], contacting people diagnosed with HIV to promote presentation to care [41], or using mobile apps to connect people newly diagnosed with HIV with support programs 
in their community [42]. These interventions need to promote presentation to care among the populations identified as underserved, specifically women and people with mental health conditions.

Acknowledgements This study was supported by the Institute for Clinical Evaluative Sciences (ICES), which is funded by an annual grant from the Ontario Ministry of Health and Long-Term Care (MOHLTC). The opinions, results and conclusions reported in this paper are those of the authors and are independent from the funding sources. No endorsement by ICES or the Ontario MOHLTC is intended or should be inferred.

Disclaimer The authors are solely responsible for the content of the article.

Funding The study was funded by the Canadian Institutes of Health Research (CIHR) FRN TT5-128270. JR was supported by an OHTN Chair in Biostatistics.

\section{Compliance with Ethical Standards}

Conflict of interest The authors have no conflicts of interest to declare.

Ethical approval The study was approved by the Research Ethics Board of Sunnybrook Health Sciences Centre, Toronto, Ontario. All study procedures were in accordance with the ethical standards of the Research Ethics Board and with the 1964 Helsinki declaration and its later amendments.

Informed consent Informed consent was not required because no patient identifiable data were obtained.

Open Access This article is distributed under the terms of the Creative Commons Attribution 4.0 International License (http://creativeco mmons.org/licenses/by/4.0/), which permits unrestricted use, distribution, and reproduction in any medium, provided you give appropriate credit to the original author(s) and the source, provide a link to the Creative Commons license, and indicate if changes were made.

\section{References}

1. Gardner EM, McLees MP, Steiner JF, Del Rio C, Burman WJ. The spectrum of engagement in HIV care and its relevance to test-and-treat strategies for prevention of HIV infection. Clin Infec Dis. 2011;52(6):793-800. https://doi.org/10.1093/cid/ciq243.

2. UNAIDS. 90-90-90: An Ambitious Treatment Target to Help End the AIDS Epidemic. Geneva, Switzerland; 2014.

3. Deeks SG, Lewin SR, Havlir DV. The end of AIDS: HIV infection as a chronic disease. Lancet. 2013;382(9903):1525-33. https:// doi.org/10.1016/S0140-6736(13)61809-7.

4. Andrews JR, Wood R, Bekker LG, Middelkoop K, Walensky RP. Projecting the benefits of antiretroviral therapy for HIV prevention: The impact of population mobility and linkage to care. J Infect Dis. 2012;206(4):543-51. https://doi.org/10.1093/ infdis/jis401.

5. Yehia B, Frank I. Battling AIDS in America: an evaluation of the National HIV/AIDS Strategy. Am J Public Health. 2011;101(9):e4-8.
6. Tanner AE, Mann L, Song E, et al. Wecare: A social mediabased intervention designed to increase HIV care linkage, retention, and health outcomes for racially and ethnically diverse young MSM. AIDS Educ Prev. 2016;28(3):216-30. https://doi. org/10.1521/aeap.2016.28.3.216.

7. Burchell AN, Gardner S, Light L, et al. Engagement in HIV care among persons enrolled in a clinical HIV cohort in Ontario, Canada, 2001-2011. J Acquir Immune Defic Syndr. 2015;70(1):10-9. https://doi.org/10.1097/QAI.0000000000 000690 .

8. Zanoni BC, Mayer KH. The adolescent and young adult HIV cascade of care in the United States: exaggerated health disparities. AIDS Patient Care STDS. 2014;28:128-35.

9. Seekins D, Stryker R, Lovvoll V. Estimation of the size and treatment status of the HIV population in the United States. Presented at: 48th Annual Meeting of IDSA 21-4 October 2010; Vancouver, WA. Presentation 1064

10. Johnston SS, Juday T, Seekins D, et al. Patterns and correlates of linkage to appropriate HIV care after HIV diagnosis in the US Medicaid population. Sex Transm Dis. 2013;40(1):18-25. https ://doi.org/10.1097/OLQ.0b013e3182782014.

11. Gerver SM, Easterbrook PJ, Anderson M, et al. Sexual risk behaviours and sexual health outcomes among heterosexual black caribbeans: comparing sexually transmitted infection clinic attendees and national probability survey respondents. Int J STD AIDS. 2011;22:85-90.

12. Ulett KB, Willig JH, Lin HY, et al. The therapeutic implications of timely linkage and early retention in HIV care. AIDS Patient Care STDS. 2009;23:41-9.

13. Bhatia R, Hartman C, Kallen MA, Graham J, Giordano TP. Persons newly diagnosed with HIV infection are at high risk for depression and poor linkage to care: results from the steps study. AIDS Behav. 2011;15(6):1161-70. https://doi.org/10.1007/s1046 1-010-9778-9.

14. Chander G, Himelhoch S, Moore RD. Substance abuse and psychiatric disorders in HIV-positive patients: Epidemiology and impact on antiretroviral therapy. Drugs. 2006;66:769Y789.

15. Cunningham WE, Drainoni M, Cunningham CO, Eldred L, Wong MD. Health Services Utilization for People with HIV Infection. Med Care. 2006;44(11):1038-47.

16. Wilson LE, Korthuis T, Fleishman JA, et al. HIV-related medical service use by rural/urban residents: a multistate perspective. AIDS Care. 2011;23(8):971-9. https://doi.org/10.1080/09540 121.2010.543878.

17. Colasanti J, Goswami ND, Khoubian JJ, et al. The Perilous Road from HIV Diagnosis in the Hospital to Viral Suppression in the Outpatient Clinic. AIDS Res Hum Retroviruses. 2016;32(8):729_ 36. https://doi.org/10.1089/AID.2015.0346.

18. Khoury Z, Silva RS, Villela W. Factors associated with a delay in seeking HIV/AIDS treatment in Sao Paulo, Brazil. AIDS Behav. 2015;19:679-83. https://doi.org/10.1007/s10461-014-0885-x.

19. Kozak M, Zinski A, Leeper C, Willig JH, Mugavero MJ. Late diagnosis, delayed presentation and late presentation in HIV: proposed definitions, methodological considerations and health implications. Antivir Ther. 2013;18(1):17-23. https://doi.org/10.3851/ IMP2534.

20. Rangarajan S, Tram HN, Todd CS, Thinh T, Hung V, Hieu PT, Hanh TM, Chau KM, Lam ND, Hung PT, West G, Colby D. Risk factors for delayed entrance into care after diagnosis among patients with late-stage HIV disease in Southern Vietnam. PLoS ONE. 2014;9(10):e108939. https://doi.org/10.1371/journ al.pone.0108939.

21. Neduzhko O, Postnov O, Perehinets I, et al. Factors Associated with Delayed Enrollment in HIV Medical Care among HIV-Positive Individuals in Odessa Region, Ukraine. J Int Assoc Provid 
AIDS Care. 2017;16(2):168-73. https://doi.org/10.1177/23259 57416686194.

22. Yehia B, Frank I. Battling AIDS in America: an evaluation of the National HIV/AIDS Strategy. Am J Public Health. 2011;101(9):e4-8.

23. Zou G. A modified poisson regression approach to prospective studies with binary data. Am J Epidemiol. 2004;159:702-6.

24. Kralj B. Measuring, "rurality" for purposes of health care planning: an empirical measure for Ontario. Ont Med Rev. 2000;67(9):33-52.

25. Starfield B, Weiner J, Mumford L, Steinwachs D. Ambulatory care groups: a categorization of diagnoses for research and management. Health Serv Res. 1991;26(1):53-74.

26. Steele LS, Glazier RH, Lin E, Evans M. Using administrative data to measure ambulatory mental health service provision in primary care. Med Care. 2004;42(10):960-5.

27. SAS/STAT Software, Version 9.3. 2011. SAS Institute Inc., Cary, North Carolina, USA.

28. Aziz M, Smith KY. Challenges and successes in linking HIVinfected women to care in the United States. Clin Infect Dis. 2011;52(suppl. 2):S231-7.

29. Moore RD. Epidemiology of HIV infection in the United States: Implications for linkage to care. Clin Infect Dis. 2011;52(SUPPL. 2):S208-13. https://doi.org/10.1093/cid/ciq044.

30. Hader SL, Smith DK, Moore JS, Holmberg SD. HIV infection in women in the United States: status at the Millennium. JAMA. 2001;285:1186-92.

31. Raboud J, Blitz S, Antoniou T, Loutfy M, Walmsley S. Recent immigrants show improved clinical outcomes at a tertiary care HIV clinic. Can J Infectious Dis Med Microbiol. 2012;23:9-14.

32. Worthington C, Este D, Strain KL, et al. African immigrant views of HIV service needs: gendered perspectives. AIDS Care. 2013;25:103-8.

33. Reid R, Evans E, Barer M, Sheps S, Kerluke K, McGrail K, Hertzman C, Pagliccia N. Conspicuous consumption: characterizing high users of physician services in one Canadian province. J Health Serv Res Policy. 2003;8(4):215-24. https://doi. org/10.1258/135581903322403281.
34. Blashill AJ, Perry N, Safren SA. Mental health: a focus on stress, coping and mental illness as it relates to treatment retention, adherence, and other health outcomes. Curr HIV/AIDS Rep. 2011;8:215-22.

35. Yehia BR, Stewart L, Momplaisir F, Mody A, Holtzman CW, Jacobs LM, Hines J, et al. Barriers and facilitators to patient retention in HIV care. BMC Infect Dis. 2015;15:246.

36. Lau C, Kurdyak P, Kendall CE, Bayoumi AM, Burchell AN, Loufty $\mathrm{M}$, et al. Health service outcomes among persons with HIV following a mental health admission: a population-based study. Abstract presented at the 25th Annual Canadian Conference on HIV/AIDS (CAHR), Winnipeg, Canada, May, 2016. Abstract: CSP10.01.

37. Vigod SN, Kurdyak PA, Dennis CL, Leszcz T, Taylor VH, Blumberger DM, et al. Transitional interventions to reduce early psychiatric readmissions in adults: systematic review. Br J Psychiatr. 2013;202:187-94.

38. Ontario Ministry of Health and Long-Term Care. HIV and AIDS. Ontario HIV/AIDS Infection Rates. 2016. Accessed June 19, 2017 from http://www.health.gov.on.ca/en/public/programs/hivaids/ charact_epidemic.aspx.

39. Skarbinski J, Rosenberg E, Paz-Bailey G, et al. Human immunodeficiency virus transmission at each step of the care continuum in the United States. JAMA Intern Med. 2015;175(4):588-96. https ://doi.org/10.1001/jamainternmed.2014.8180.

40. Pilcher CD, Ospina-Norvell C, Dasgupta A, et al. The effect of same-day observed initiation of antiretroviral therapy on HIV viral load and treatment outcomes in a U.S. public health setting. $\mathrm{J}$ Acquir Immune Defic Syndr. 2017;74(1):44-51.

41. Van Zyl MA, Brown LL, Pahl K. Using a call center to encourage linkage to care following mobile HIV counseling and testing. AIDS Care. 2015;27(7):921-5. https://doi.org/10.1080/09540 121.2015.1015483.

42. Buzi RS, Smith PB, Siceluff A. A participatory learning and action (PLA) approach to enhancing linkage to HIV care among youth. J Adolesc Heal. 2016;58(2):S82. https://doi.org/10.1016/j. jadohealth.2015.10.176. 